\title{
Management of Multiple Ecosystem Services under Climate Change, Bioeconomy and Participation
}

\author{
Emin Zeki Baskent ${ }^{1, *,+}\left(\mathbb{D}\right.$, José Guilherme Borges ${ }^{2}\left(\right.$, Harald Vacik ${ }^{3}{ }^{\oplus}$, Keith M. Reynolds $^{4}(\mathbb{D}$ \\ and Luiz Carlos E. Rodriguez ${ }^{5}$ \\ 1 Former Professor of Faculty of Forestry, Karadeniz Technical University, 61080 Trabzon, Turkey \\ 2 Forest Research Centre, School of Agriculture, University of Lisbon, 1349-017 Lisbon, Portugal; \\ joseborges@isa.ulisboa.pt \\ 3 Department of Forest and Soil Sciences, Institute of Silviculture, University of Natural Resources and Life Sciences, \\ A-1190 Vienna, Austria; harald.vacik@boku.ac.at \\ 4 USDA Forest Service, Pacific Northwest Research Station, Corvallis, OR 97331, USA; \\ keith.reynolds2@usda.gov \\ 5 Departamento de Ciências Florestais, ESALQ, University of Sao Paulo, Av. Pádua Dias, 11-LCF/ESALQ/USP, \\ Piracicaba, SP, São Paulo 13418-900, Brazil; lcer@usp.br \\ * Correspondence: eminzekibaskent@gmail.com; Tel.: +90-535-486-8194 \\ + Current address: Department of Forest Management, Faculty of Forest and Wood Sciences, Czech University \\ of Life Sciences Prague, Kamycka 129, 16500 Prague, Czech Republic.
}

Citation: Baskent, E.Z.; Borges, J.G.; Vacik, H.; Reynolds, K.M.; Rodriguez, L.C.E. Management of Multiple Ecosystem Services under Climate Change, Bioeconomy and Participation. Forests 2021, 12, 104. https://doi.org/10.3390/f12010104

Received: 15 December 2020

Accepted: 16 January 2021

Published: 19 January 2021

Publisher's Note: MDPI stays neutral with regard to jurisdictional clai$\mathrm{ms}$ in published maps and institutional affiliations.

Copyright: $(\odot 2021$ by the authors. Licensee MDPI, Basel, Switzerland. This article is an open access article distributed under the terms and conditions of the Creative Commons Attribution (CC BY) license (https:// creativecommons.org/licenses/by/ $4.0 /)$.

\begin{abstract}
The Special Issue "Decision Support to Address Multiple Ecosystem Services in Forest Management Planning" includes nine research papers, two review papers, and a white paper presenting highlights of focused research initiatives. The papers provide a comprehensive framework for the analysis and review of advanced Decision Support Systems (DSS), which are multi-criteria decision approaches. Their emphasis is on how these methods and tools may contribute to address the multi-functionality of forests, to support scenario and trade-off analysis of ecosystem services, and to represent interests and behavior of various stakeholders. In the context of forest ecosystem management, a need has arisen to consider various dimensions in the design of the planning process. This calls for the development of appropriate mixes of decision making tools and methods and for its testing with the support of case studies. In this Special Issue, comments on, and implications of, the improvement of innovative decision methods and systems to address the provision of a wide range of ecosystem services and support scenario analysis with the active involvement of stakeholders are presented.
\end{abstract}

Keywords: ecosystem services; modeling; multiple-criteria methods; decision support system; forest management planning

\section{Introduction}

Increasing demand for various ecosystem services (e.g., conservation of biodiversity, recreation and provision of timber among others), while addressing the impacts of management interventions and natural disturbances on future forest conditions and ecosystem services (ES), poses a major challenge in forest management planning. The challenge can be met by developing a conceptual framework for ecosystem management that may be implemented by information systems to help analyze alternative management options and support a structured participation for responsible action. The framework reflects the dimensions of the forest management planning problem as well as the relationships of components of the planning process. An effective information system provides the necessary combination of tools and techniques to formulate complex decision problems, and it takes advantage of the integrated functionality of spatial database management systems, simulation tools, and management science techniques to forecast the consequences of various courses of actions on forest dynamics and to provide different reporting capabilities for 
visualization and documentation of management decisions. Case studies provide opportunities to test the validity of the theoretical foresight and conceptual design of management interventions and to assess the results and implications of various management options, including climate change effects through trade-off or scenario analysis with stakeholder participation. The literature reports several innovative decision support methods and tools targeting the increase of the efficiency and the effectiveness of forest management planning [1-12].

The contribution of the Special Issue to the state-of-the-art lies in its examination of various frameworks, models, tools, and techniques and on the demonstration of their functionality in several contexts and case studies. The Special Issue covers various scientific endeavors and achievements that may be summarized and structured around three main sections: (i) framework and multifunctionality of forests, (ii) multi-criteria methods and decision support systems, and (iii) case studies with simulation and scenario analysis. In the first section, the conceptual development of a framework for forest ecosystem management is highlighted. The benefits of species mixing for achieving desired levels and combinations of ecosystem service provision, productivity, diversity, and groundwater recharge are also addressed to help improve current understanding of forest dynamics under both natural disturbances and management interventions. In the second section, the recent developments in decision support approaches in forest management, targeting the provision of ecosystem services are reported. In the third section, the integration of non-wood forest products (NWFP) in forest management is explored providing new scientific contributions to the management of ecosystems. This section also explores approaches to address concerns about the provision of ecosystem services under climate change and forest owner behavior scenarios with the support of simulation, and multi-criteria decision analysis (MCDA).

\section{Framework and Multifunctionality of Forests}

Moving rapidly from traditional wood-based forest management concepts towards holistic consideration of multiple ecosystem services has steadily gained prominence in forest management over the past 20 years. However, few attempts have been made to design a framework for forest management that comprehensively accounts for characterizing and addressing ecosystem services in forest management planning. Baskent [13] has developed a conceptual framework for characterizing ecosystem services for their integration into the multiple-use forest management planning process. He reviews various classification systems and summarized the available quantification methods of prominent ecosystem services. He highlights that identifying and quantifying ecosystem services in a common platform with direct or proxy measures before integrating them into a decision making environment is an important prerequisite to initiate the design of a multiple-use forest management plan. Similarly, Baskent et al. [12] postulates a design for conceptualizing key dimensions such as decision making context, compositional context, temporal context, spatial scale, and spatial context of the framework. They emphasize the need for a multi-level perspective; appropriate spatial resolution, structured involvement of key stakeholders; harmonization of hierarchical planning processes; the appropriate methods and tools for encapsulating the ecological, economic, and social complexity of forest ecosystem management to provide an efficient plan; information about tradeoffs between ecosystem services; and the sensitivity of the plan to uncertain parameters (e.g., prices, climate change). Benz et al. [14] analyze the views and experiences of scientists and forest practitioners in Germany and China in terms of the multi-faceted nature of forest management and the tools used to analyze various aspects of multifunctionality, including economic evaluations of ES, afforestation, and restoration to address climate change, and participation of local people for poverty reduction. They have highlighted that multi-functionality is a central goal of sustainable forest management under dynamic social and environmental conditions; biodiversity conservation and climate change are the bases, and an integral part of, the overall planning process; multiple actor-based multi-criteria scenario analysis 
is a requirement for knowledge-based planning; and new silvicultural tools are needed to balance ecological, economic, and social expectations adapted to local conditions.

Schwaiger et al. [15] propose an approach to regulate proportions of species mixtures for achieving desired levels and combinations of ES provision such as productivity, diversity, and groundwater recharge using a simulation approach with species-specific development of height, diameter, and crown projection area. Interestingly, they have demonstrated that a constant $50 \%$ basal area share of beech provided the most balanced supply of ES. Their methodological approach to regulate mixture rate provides a practical solution to the practitioners, and is suitable for identifying trade-offs between various ecosystem services in multifunctional forest management by bridging the gap between science and practice.

Aside from characterization of ES, valuation of ES has also gained prominence in forest management planning because many forest ES are public goods or positive externalities. According to Müller et al. [16], the valuation of forest ES can provide important information for decision making in forest management planning, setting up policies and developing mechanisms for financial incentives. Based on a literature review, they have explored opportunities to develop models for economic valuation of forest ES. They indicate that existing models or estimates and the databases are insufficient, calling for the need to specify in detail the background conditions of case studies and indicators used for valuation. In any case, ES should be an integral part of forest management and planning, and their financial values should be considered in decision-making processes because the economic valuation of forest ES can help make their value visible and raise awareness in society [16].

\section{Multi-Criteria Methods and Decision Support Systems}

DSS are indispensable tools in preparing management plans under various scenarios to achieve management objectives subject to various constraints and come up with an optimal or near optimal solution. They have been regularly improved by accommodating new modeling features such as accounting for spatial features, combinatorial optimization techniques, web-based scenario analysis with Pareto frontiers, integration of multiple ecosystem services with their financial valuations, and additional display and mapping capabilities regarding the review of the state-of-art of DSS. Recently, a number of decision making techniques have been combined to help stakeholders select the best set of ecosystem services (wood production, biodiversity, and carbon sequestration). For example, Marto et al. [7] have hybridized knowledge-based logic-modeling approaches encapsulated in ecosystem management decision support (EMDS) and a multiple-criteria Pareto frontier method with SADfLOR DSS to realize the potential of the combination of the decision approaches to support collaborative forest ecosystem management planning. EMDS is used to choose the best non-dominated solution among a set of alternatives generated by the Pareto frontier tool in SADfLOR to strengthen the collaborative planning process, and to support the negotiation needed to reach a consensus solution.

A freeware web-based system (wSADfLOR) is presented by Marto el al. [17] to support trade-off analyses between ecosystem services in the form of decision maps and participatory and collaborative forest management planning so that users in different remote locations can negotiate a set of ES for the plan area. They show that the web-based features of the DSS provide effective access for stakeholders to information about the area and to decision support tools that may contribute to addressing complex multi-objective contexts with transparent management planning suitable for use with multiple decision makers.

An interesting study conducted by Chen et al. [18] used machine learning and an expert system to automatically extract rules for selecting favorable site conditions for afforestation. The consistency of rules and site index was found to be near 70 . They provide the theoretical basis and technical support for afforestation planning and design.

Furthermore, Merganic et al. [19] analyzed the impact of four forest management scenarios (clear-cutting, shelter-wood, selection cutting, and no-cutting) on wind stability, timber production, and biodiversity in stands as management criteria/objectives. They inte- 
grated stand level simulation (SIBYLA) with a MCDA tool (OPTIMUS) to construct Pareto frontiers for assessing compromises in forest management. They indicated substantial trade-offs among the three criteria and found that the decision space is very sensitive to the weighting system.

\section{Case Studies with Simulation and Scenario Analysis}

Simulation systems have been widely used to project the future provision of goods and services and analyze the effect of changing forest policies or even the impacts of climate change. Lodin et al. [20] investigated the extent of increasing wood demands under defined climate change mitigation scenarios with different management intensities in Sweden using the Heureka Planwise DSS system. They showed that the achievement of traditional forest management objectives is truly limited to the projected climate change scenarios. Specifically, future wood demand could not be met with current management practices under ambitious mitigation scenario at the intensive extreme of current management approaches, calling for the redesign of current management policies and strategies to address climate change effects.

Mozgeris et al. [21] investigated climate change and its impacts on the sustainability of forest management (forest growth, global timber demands and prices) in a Lithuanian forest ecosystem with three climate change scenarios using an in-house forest simulator called Kupolis. Because the case study area is in the Northern hemisphere, a warmer climate change effect is found to increase tree size, stand productivity, and growing stock, resulting in higher profits yet negative dynamics of biodiversity (decrease broadleaf cover and tree species diversity). Interestingly, they confirmed the geographic context and spatial scale to be important in dealing with climate change effects, which resulted in spatially clustered patterns of management options. Specifically, the amount of harvested timber is concentrated in the regions with dominating coniferous species, while the same areas are exposed to stronger negative impacts on dynamics of biodiversity-related attributes. They also found that decisions on the felling rate due to climate change over time vary according to local ecological conditions and policy requirement. They finally suggest developing different forest management strategies for regions with different forest characteristics.

Nyongesa and Vacik [22] developed a methodological approach using the MCDA approach of the Analytical Hierarchy Process (AHP) with a set of objectives and criteria to address the complexity of the decision problem in a Forest reserve and National Park in Kenya. They evaluated seven management strategies focusing on climate change mitigation, protection of water catchments, education and research, stakeholder involvement, biodiversity conservation, timber production, and community interests, and selected the best management strategy to reduce fire danger and increase the social benefits based on the preferences of all stakeholder groups. They indicated that MCDA is an appropriate and useful approach for capturing diverse views, objectives, and perspectives of different stakeholders, and their approach minimized information gaps between decision-makers, both at local and national levels, thus facilitating effective participation by diverse professionals, experts, and interest groups.

Kurttila et al. [23] used MCDA to analyze the synergies and trade-offs between timber production and different NWFPs, such as different berries, mushrooms, and treebased products, by generating a large number of Pareto optimal management plans with a multi-objective optimization tool. They found that the maximum yields of NWFPs are achieved with rather high cutting rates; severe trade-offs were only found at nearmaximal production levels, and the joint-production of NWFPs and timber was found to be more profitable.

\section{Discussion and Conclusions}

Support for improved forest ecosystem management for multiple ecosystem services continues to gain prominence in forest research, and there is a need to design a more holistic framework that may help address the complexity of ecosystem management planning 
processes, namely, its spatial and temporal scales, the range or ecosystem services and objectives, as well as its participatory dimension. The critical role of information systems and DSS, consisting of a mix of decision making tools and methods, is still increasing as an improved approach to determining the best combination of multiple ecosystem services, helping evaluate appropriate numbers of management scenarios/strategies, and allowing actors to actively participate in the decision making process in multifunctional forestry. The various contexts and dimensions of forest planning, considering scale, resolution, and level of information/data, require a diverse assortment of decision making techniques to arrive at appropriate solutions for a variety of contexts. There is still a need to characterize ecosystem services comprehensively and practically in a form that better integrates with forest management planning. Ecosystem management requires dynamic projection of growth and development of forest ecosystems under changing climate, price, and environmental conditions, with risk and uncertainties considered. Ultimately, accurate decision making requires extensive coverage of the decision space, understanding forest dynamics (cause-effect relationships), and wider participation/discussion of informed stakeholders.

This Special Issue highlights that the development of a sound/comprehensive decision making framework for forest ecosystem management provides the theoretical basis for realizing multifunctionality through a combination of data acquisition and management technologies, decision making tools and methods, and trade-off analysis capability with the structural participation of stakeholders and actors. Demands for the improved development and application of versatile DSS are continuing challenges for both scientists and practitioners to better translate theoretical underpinnings to reality on the ground. The papers show that versatile and practical DSS are needed that include multi-criteria decision analysis approaches that support a multi-functional management of the forests considering the wide variety of ecosystem services provided, namely, NWFP. This is in concordance with the findings in the literature that reports the importance of NWFP such as berries, fruits, medicinal herbs, and mushrooms as provisioning ecosystem services [24] and the development of yield models for different NWFPs and their encapsulation in forest simulators $[25,26]$. Utilizing scenario and trade-off analysis in the provision of sometimes contrasting ecosystem services addressing the interests of various stakeholder groups is becoming more important and necessary, perhaps more than ever before. They present some emerging challenges in forest management planning, such as accommodating climate change impacts in forest planning, machine learning for automatic extraction of rules, web-based DSS tools supporting wider and distant involvement of users in decision making processes, multi-criteria analysis to compare multiple ES, integration of NWFP into planning, and valuation of ES for better decision making in forest management planning. Furthermore, it has been stated that multi-functionality is the goal of sustainable forest management under dynamic social and environmental conditions, regulation of species mixture proportions is critical for achieving desired levels, and combinations of ecosystem service and structured participation and policy framework are still the emerging challenges in decision making process.

A number of DSS-related conferences (Vienna 2003, Edinburgh 2005, Lisbon 2009, Umea 2013, Prague 2018) have demonstrated various aspects of decision support in forest management applications in a wider context $[3,27,28]$. In fact, development of DSS frameworks that simultaneously model the three dimensions of forest management problem (knowledge management; adaptive management; and multi-lateral goals, criteria, and stakeholders) with scenario analysis is challenging [10]. The system strongly relies on (i) knowledge management (KM) supported by information technology to deal with the huge amount of data that describes the territory, silvicultural activities, and production over time as proposed by McDill [29]; and (ii) adaptive management monitoring processes that integrate and allow for the comparison of the information used in supporting a decision with important outcomes. In fact, the potential conflicts that arise between the desire for conservation and utilization of natural resources make the triple strategy essential. This Special Issue is in line with the general scope and challenges identified in the last 
decades. The need to focus on targeted audiences for developing successful DSS applications forces scientists, decision analysts, and IT specialist to tailor the decision support tools to increasing and widening user needs $[8,10,17]$. A "toolbox" approach, which allows one to combine various decision support tools that support different phases of the decision making process, will become therefore more important in the future [30]. The exchange of experiences and lessons learned from the development and application of such tools is a relevant aspect in forest science domain. The working groups of IUFRO [31,32] and the Community of Practice of Forest Management Decision Support Systems [33] have a well-established user community, with members from research, public bodies, business, and non-governmental organizations. The reader is welcome to contribute to the continuation of the network activities in connecting and mobilizing developers and users of DSS to support the planning and sustainable use of forest resources in a changing world.

Author Contributions: E.Z.B., J.G.B., H.V., K.M.R., and L.C.E.R. designed the contributions to the Special Issue and interpreted the results. E.Z.B. drafted the paper, and all co-authors contributed to the writing of the final version. All authors have read and agreed to the published version of the manuscript.

Funding: This research received no external funding.

Institutional Review Board Statement: Not applicable.

Informed Consent Statement: Not applicable.

Data Availability Statement: Data sharing not applicable.

Acknowledgments: The authors would like to thank all authors contributing to this Special Issue and for providing vision and new understanding on Forest Management Decision Support Systems applied to provide sustainable use of ecosystem services within the context of climate change and participatory planning. Special thank goes to the Journal Editors of Forests for providing substantial support in handling the manuscripts and reviews. The authors would also like to thank the sponsorship by IUFRO units 4.04.04 (Sustainable Forest Management Scheduling). This work received support of the Centro de Estudos Florestais, a research unit funded by Fundação para a Ciência e a Tecnologia I.P. (FCT), Portugal (UIDB/00239/2020), and of the BIOECOSYS project, "Forest Ecosystem Management Decision-Making Methods: An Integrated Bioeconomic Approach to Sustainability" (LISBOA-010145-FEDER-030391, PTDC/ASP-SIL/30391/2017). This paper was also supported by the EVA4.0 project, "Advanced Research Supporting the Forestry and Wood-Processing Sector's Adaptation to Global Change and the 4th Industrial Revolution" (CZ.02.1.01/0.0/0.0/16_019/0000803) in the Czech University of Life Sciences, Prague.

Conflicts of Interest: The authors declare no conflict of interest.

\section{References}

1. Reynolds, K.M.; Twery, M.; Lexer, M.J.; Vacik, H.; Ray, D.; Shao, G.; Borges, J.G. Decision Support Systems in Forest Management, 2008, 2: 499-533. In Handbook on Decision Support Systems 2; Burstein, F., Holsapple, C., Eds.; Springer: Berlin/Heidelberg, Germany, 2008; 798p, ISBN 978-3-540-48716-6.

2. Borges, J.G.; Eriksson, L.O. Decision support systems for sustainable forest management. Scand. J. For. Res. 2014, 29. [CrossRef]

3. Vacik, H.; Borges, J.G.; Garcia-Gonzalo, J.; Eriksson, O. Decision Support for the Provision of Ecosystem Services under Climate Change: An Editorial. Forests 2015, 6, 3212-3217. [CrossRef]

4. Borges, J.G.; Marques, S.; Garcia-Gonzalo, J.; Rahman, A.U.; Bushenkov, V.; Sottomayor, M.; Carvalho, P.O.; Nordstrom, E.M. A Multiple Criteria Approach for Negotiating Ecosystem Services Supply Targets and Forest Owners' Programs. For. Sci. 2017, 63, 49-61. [CrossRef]

5. Orazio, C.; Cordero Montoya, R.; Régolini, M.; Borges, J.G.; Garcia-Gonzalo, J.; Barreiro, S.; Botequim, B.; Marques, S.; Sedmák, R.; Brodrechtová, Y.; et al. Decision Support Tools and Strategies to Simulate Forest Landscape Evolutions Integrating Forest Owner Behavior: A Review from the Case Studies of the European Project, INTEGRAL. Sustainability 2017, 9, 599. [CrossRef]

6. Kaspar, J.; Bettinger, P.; Vacik, H.; Marusak, R.; Garcia-Gonzalo, J. Decision Support Approaches in Adaptive Forest Management. Forests 2018, 9, 215. [CrossRef]

7. Marto, M.; Reynolds, K.M.; Borges, J.G.; Bushenkov, V.A.; Marques, S. Combining Decision Support Approaches for Optimizing the Selection of Bundles of Ecosystem Services. Forests 2018, 9, 438. [CrossRef] 
8. Nordström, E.M.; Nieuwenhuis, M.; Baskent, E.Z.; Biber, P.; Black, K.; Borges, J.G.; Bugalho, M.N.; Corradini, G.; Corrigan, E.; Eriksson, O. Forest decision support systems for the analysis of ecosystem services provisioning at the landscape scale under global climate and market change scenarios. Eur. J. For. Res. 2019, 138, 561-581. [CrossRef]

9. Ortiz-Urbina, E.; González-Pachón, J.; Diaz-Balteiro, L. Decision-Making in Forestry: A review of the hybridization of multiple criteria and group decision-making techniques. Forests 2019, 10, 375. [CrossRef]

10. Nobre, S.R. Forest Management Decision Support System for Forest Plantation in Brazil: A Multicriteria Approach; Universidad Politécnica de Madrid: Madrid, Spain, 2019. [CrossRef]

11. Yoshimoto, A.; Patrick, A. Focal-Point Aggregation under Area Restrictions through Spatially Constrained Optimal Harvest Scheduling. For. Sci. 2019, 65, 164-177. [CrossRef]

12. Baskent, E.Z.; Borges, J.B.; Kaspar, J.; Tahri, M. A Design for Addressing Multiple Ecosystem Services in a Management Planning Context. Forests 2020, 11, 1108. [CrossRef]

13. Baskent, E.Z. A Framework for Characterizing and Regulating Ecosystem Services in a Management Planning Context. Forests 2020, 11, 102. [CrossRef]

14. Benz, J.; Chen, S.; Dang, S.; Dieter, M.; Labelle, E.R.; Liu, G.; Hou, L.; Mosandl, R.M.; Pretzsch, H.; Pukall, K.; et al. Multifunctionality of Forests: A White Paper on Challenges and Opportunities in China and Germany. Forests 2020, 11, 302. [CrossRef]

15. Schwaiger, F.; Poschenrieder, W.; Biber, P.; Pretzsch, H. Species Mixing Regulation with Respect to Forest Ecosystem Service Provision. Forests 2018, 9, 632. [CrossRef]

16. Müller, A.; Knoke, T.; Olschewski, R. Can Existing Estimates for Ecosystem Service Values Inform Forest Management? Forests 2019, 10, 132. [CrossRef]

17. Marto, M.; Reynolds, K.M.; Borges, J.G.; Bushenkov, V.A.; Marques, S.; Marques, M.; Barreiro, S.; Botequim, B.; Tomé, M. Web-Based Forest Resources Management Decision Support System. Forests 2019, 10, 1079. [CrossRef]

18. Chen, Y.; Wu, B.; Chen, D.; Qi, Y. Using Machine Learning to Assess Site Suitability for Afforestation with Particular Species. Forests 2019, 10, 739. [CrossRef]

19. Merganic, J.; Merganicová, K.; Výbošt'ok, J.; Valent, P.; Bahýl', J.; Yousefpour, R. Searching for Pareto Fronts for Forest Stand Wind Stability by Incorporating Timber and Biodiversity Values. Forests 2020, 11, 583. [CrossRef]

20. Lodin, I.; Eriksson, L.O.; Forsell, N.; Korosuo, A. Combining Climate Change Mitigation Scenarios with Current Forest Owner Behavior: A Scenario Study from a Region in Southern Sweden. Forests 2020, 11, 346. [CrossRef]

21. Mozgerisi, G.; Brukas, V.; Pivoriunas, N.; Cinga, G.; Makrickiene, E.; Bycenkien, S.; Marozas, V.; Mikalajunas, M.; Dudoitis, V.; Ulevicius, V.; et al. Spatial Pattern of Climate Change Effects on Lithuanian Forestry. Forests 2019, 10, 809. [CrossRef]

22. Nyongesa, K.W.; Vacik, H. Evaluating Management Strategies for Mount Kenya Forest Reserve and National Park to Reduce Fire Danger and Address Interests of Various Stakeholders. Forests 2019, 10, 426. [CrossRef]

23. Kurttila, M.; Pukkala, T.; Miina, J. Synergies and Trade-Offs in the Production of NWFPs Predicted in Boreal Forests. Forests 2018, 9, 417. [CrossRef]

24. Sheppard, J.; Chamberlain, J.; Agúndez, D.; Bhattacharya, P.; Chirwa, P.W.; Gontcharov, A.; Sagona, W.C.J.; Shen, H.; Tadesse, W.; Mutke, S. Sustainable Forest Management Beyond the Timber-Oriented Status Quo: Transitioning to Co-production of Timber and Non-wood Forest Products-A Global Perspective. Curr. For. Rep. 2020, 6, 26-40. [CrossRef]

25. Kurttila, M.; Tahvanainen, V. (Eds.) Description of New Decision Support Tools for Optimization of MPT and NWFP Management. Deliverable 2.4 of the STARTREE Project; Technical Report for European Commission; European Commission: Brussels, Belgium, 2016; p. 106.

26. Küçüker, D.M.; Baskent, E.Z. Sustaining the joint production of timber and Lactarius mushroom: A case study of a forest management planning unit in Northwestern Turkey. Sustainability 2017, 9, 92. [CrossRef]

27. Rauscher, M.H.; Reynolds, K.M.; Vacik, H. Decision support systems for forest management. Comput. Electron. Agric. 2005, 49, 1-5. [CrossRef]

28. Borges, J.G.; Garcia-Gonzalo, J.; Bushenkov, V.; McDill, M.E.; Marques, S.; Oliveira, M.M. Addressing Multi-criteria Forest Management with Pareto Frontier Methods: An Application in Portugal. For. Sci. 2014, 60, 63-72.

29. McDill, M. An Overview of Forest Management Planning and Information Management. In The Management of Industrial Forest Plantations; Borges, G.J., Diaz-Balteiro, L., McDill, E.M., Rodriguez, C.E.L., Eds.; Springer: Dordrecht, The Netherlands, $2014 ;$ pp. 27-59. [CrossRef]

30. Vacik, H.; Lexer, M.J. Past, current and future drivers for the development of decision support systems in forest management. Scand. J. For. Res. 2014, 29, 2-19. [CrossRef]

31. URL-1. IUFRO Working Group: Uncertainty Analysis, Computational Ecology, and Decision Support. Available online: https:/ / www.iufro.org/science/divisions/division-4/40000/40300/ (accessed on 20 November 2020).

32. URL-2. IUFRO Working Group: Sustainable Forest Management. Available online Coordinator of IUFRO Group Sustainable Forest Management Scheduling. Available online: http:/ /www.iufro.org/science/divisions/division-4/40000/40400/40404/ (accessed on 20 November 2020).

33. URL-3. Community of Practice of Forest Management Decision Support Systems. Available online: http://www.forestdss.org (accessed on 18 November 2020). 